\title{
Effect of long-term treatment with eyedrops for glaucoma on conjunctival bacterial flora
}

This article was published in the following Dove Press journal:

Infection and Drug Resistance

19 October 2011

Number of times this article has been viewed

\author{
Rio Honda' \\ Hiroshi Toshida' \\ Chikako Suto ${ }^{2}$ \\ Takuro Fujimaki ${ }^{2}$ \\ Tairo Kimura ${ }^{2}$ \\ Toshihiko Ohta' \\ Akira Murakami² \\ 'Department of Ophthalmology, \\ Juntendo University Shizuoka \\ Hospital, Izunokuni, Shizuoka, \\ ${ }^{2}$ Department of Ophthalmology, \\ Juntendo University School of \\ Medicine, Tokyo, Japan
}

Correspondence: Hiroshi Toshida Department of Ophthalmology, Juntendo University Shizuoka Hospital, I I 29 Izunokuni, Shizuoka 410-2295, Japan

Tel +8I 559483 III I

Fax +8I 55948335 I

Email toshida@juntendo.ac.jp
Objective: The effect of eyedrops for glaucoma on conjunctival bacterial flora was investigated by comparing a group of patients treated with such eyedrops for at least 1 year to a control group that did not use eyedrops.

Methods: In both groups, bacterial culture came from scrapings of the conjunctival sac, and the bacterial infection rate and pattern of drug resistance were determined. Findings were analyzed in various subgroups stratified by age, frequency of instillation, and concentration of antiseptic benzalkonium chloride in the eyedrops.

Results: The culture-positive rate was significantly lower in the glaucoma eyedrop group (43/119 eyes, $40.3 \%)$ than in the control group $(19 / 28$ eyes, $67.8 \%)(P<0.05)$. No differences in infection rate were found among the different age groups. The most frequent bacteria in both groups was coagulase-negative staphylococci. Gram-negative bacteria were only detected in the glaucoma eyedrop group. Retrospective evaluation was possible for 86 eyes of patients from the glaucoma eyedrop group, among which 45 eyes (52.3\%) showed some corneal epithelium damage. There was no difference in the culture-positive rate of bacteria between patients who used eyedrops containing $0.01 \%$ or higher dose of benzalkonium chloride and those containing less than $0.01 \%$. Strains that showed resistance to levofloxacin were significantly less frequent in the glaucoma eyedrop group (six strains, 15.0\%) than in the control group (11 strains, 39.3\%) $(P<0.05)$.

Conclusion: Patients using eyedrops for glaucoma had a lower culture-positive rate of bacteria in the conjunctival sac, probably due to being washed out by the eyedrops. However, Gramnegative bacteria were detected in the eyedrop group. Bacteria isolated from the eyedrop group had lower resistance to levofloxacin, a finding that may have clinical relevance.

Keywords: glaucoma, eyedrop, benzalkonium chloride, conjunctival flora, levofloxacin

\section{Introduction}

Instilling eyedrops may have various effects on the ocular surface. Patients with glaucoma need to instill eyedrops several times a day for a long period, which may have a marked effect on their eyes. Some eyedrops for glaucoma contain antiseptics at a higher concentration than that of the active ingredient, and previous reports have suggested that these antiseptics can damage the ocular surface. ${ }^{1,2}$ Eyedrops typically contain an active ingredient in a vehicle and an antiseptic. In most eyedrops, benzalkonium chloride (a cationic soap) is used as the antiseptic. ${ }^{1-4}$

In the present study, the effect of chronic use of eyedrops on conjunctival bacterial flora in patients who had instilled eyedrops to treat glaucoma for 1 year or more was investigated. After isolating bacteria from the conjunctival sac in these patients, the 
bacterial infection rate and pattern of drug resistance were compared with those in a control group.

\section{Materials and methods Patients}

The subjects were 119 patients with primary open angle glaucoma who had used eyedrops for 1 year or more and who attended the glaucoma outpatient department of Juntendo University Hospital during 6 months from April to September 2004. Declaration of Helsinki and written consent was provided by all patients. Subjects consented to a scraping specimen from one eye being sent for bacterial culture and typing. The patients in the glaucoma eyedrop group were treated with mono or combined topical therapies (prostaglandin analogs, carbonic anhydrase inhibitors, $\beta$-blockers, $\alpha 2$ agonists, and nonselective sympathetic and parasympathetic stimulants) (Table 1). Exclusion criteria included subjects with suspected inflammation of the anterior eye, subjects administered with antibiotic medicine orally, and subjects using eyedrops that were not for glaucoma, such as antibiotics or artificial tears. Further, patients with diabetes mellitus and patients treated with corticosteroids were also excluded because of easy infections and a higher number of positive conjunctival cultures. ${ }^{5}$ The control group consisted of 28 subjects who visited these hospitals during the same period, did not have glaucoma or untreated cataract, and who did not use eyedrops. Exclusion criteria were the same as described above. In the glaucoma eyedrop group, conjunctival scrapings were taken from the treated eyes, while scrapings were obtained from the right eye in the control group.

\section{Investigations}

Isolated bacteria were cultured and drug sensitivity tested using the disk diffusion method (Kirby-Bauer method) based on previous studies. ${ }^{6,7}$ The samples taken for culture from

Table I Details of antiglaucoma eyedrops and number of enrolled eyes

\begin{tabular}{|c|c|c|c|}
\hline Antiglaucoma drugs & $\begin{array}{l}\text { Instillation } \\
\text { frequency/day }\end{array}$ & BAC concentration & Enrolled eyes $(\mathbf{N})$ \\
\hline \multicolumn{4}{|l|}{ Prostaglandin analogs } \\
\hline $\begin{array}{l}\text { Latanoprost } 0.005 \% \\
\left(\text { Xalatan }^{\circledast}, \text { Pfizer Inc, New York, NY) }\right.\end{array}$ & 1 & $0.02 \%$ & 44 \\
\hline $\begin{array}{l}\text { Unoprostone isopropyl } 0.12 \% \\
\text { (Rescula }^{\circledR} \text {, Santen Pharmaceutical Co, Ltd, Osaka, Japan) }\end{array}$ & 2 & $0.01 \%$ & 23 \\
\hline \multicolumn{4}{|l|}{ Carbonic anhydrase inhibitors } \\
\hline $\begin{array}{l}\text { Dorzolamide hydrochloride } 1 \% \\
{\text { (Trusopt }{ }^{\circledR}, \text { Merck Sharp and Dohme Corp, }} \\
\text { Whitehouse Station, NJ) }\end{array}$ & 3 & $0.005 \%$ & 23 \\
\hline \multicolumn{3}{|l|}{$\left(\mathrm{Azopt}^{\circledR}\right.$, Alcon Laboratories, Inc, Fort Worth, TX) } & 1 \\
\hline \multicolumn{4}{|l|}{$\beta$-blockers } \\
\hline $\begin{array}{l}\text { Levobunolol hydrochloride } 0.5 \% \\
\text { (Mirol }^{\circledR} \text {, Kaken Pharmaceutical Co, Ltd, Tokyo, Japan) }\end{array}$ & 2 & $0.004 \%$ & 20 \\
\hline $\begin{array}{l}\text { Timolol maleate } 0.5 \% \\
\text { (Timoptol }{ }^{\circledR} \text {, Santen Pharmaceutical Co, Ltd, Osaka, Japan) }\end{array}$ & 2 & $0.005 \%$ & 18 \\
\hline \multicolumn{4}{|l|}{ (Mikelan ${ }^{\circledR}$, Otsuka Pharmaceutical Co, Ltd, Tokyo, Japan) } \\
\hline \multicolumn{4}{|l|}{ (Hypadil ${ }^{\circledR}$, Kowa Company Ltd, Tokyo, Japan) } \\
\hline \multicolumn{4}{|l|}{ (Betoptic ${ }^{\circledR}$, Alcon Laboratories) } \\
\hline \multicolumn{4}{|l|}{$\alpha$ I-blockers } \\
\hline \multicolumn{4}{|l|}{ (Detantol ${ }^{\circledR}$, Santen Pharmaceutical) } \\
\hline \multicolumn{4}{|l|}{ Parasympathetic stimulant } \\
\hline $\begin{array}{l}\text { Pilocarpine hydrochloride I\% or } 2 \% \\
\text { (Sanpilo }{ }^{\circledR} \text {, Santen Pharmaceutical) }\end{array}$ & 3 & $0 \%$ & 2 \\
\hline \multicolumn{4}{|l|}{ Sympathetic stimulant } \\
\hline $\begin{array}{l}\text { Dipivefrin hydrochloride } 0.1 \% \\
\text { (Pivalephrine }^{\circledR} \text {, Santen Pharmaceutical) }\end{array}$ & 2 & $0.05 \%$ & 2 \\
\hline
\end{tabular}

Abbreviation: BAC, benzalkonium chloride. 
the patients with bacterial keratitis were collected by one ophthalmologist (RH) using a sterile cotton swab with topical anesthesia from the lower conjunctival sac. The collected materials were routinely smeared onto slides and stained with Gram staining and streaked over the surface of blood agar, chocolate agar, and Sabouraud agar for culture. Cultures were positive if organisms were grown along the line of inoculation on the agar plates. The bacteria were identified using standard laboratory techniques. Antibiotic susceptibilities were recorded following the National Committee for Clinical Laboratory Standards method. ${ }^{8,9}$

The bacterial culture-positive rate, species of bacteria, and drug sensitivity were recorded. Subgroup analysis assessed the bacterial culture-positive rate in relation to the frequency of instillation, number of different eyedrops used, and the concentration of antiseptics contained in each eyedrop. According to the frequency of instillation, patients were classified into three groups: the control group, a group using eyedrops one to two times a day, and a group using eyedrops three or more times a day. Based on the number of types of eyedrops used, patients were also classified into three groups: the control group, a group using one type of eyedrop, and a group using two or more types of eyedrops.

Statistical analyses were performed using SPSS for Windows (v 14.0; SPSS Inc, Chicago, IL). The $2 \times 2$ Chi square test was employed for categorical comparison. Comparisons of the continuous variables between and within groups were performed by Mann-Whitney U tests.

\section{Results}

The glaucoma eyedrop group contained 119 subjects ( 52 men and 67 women) with a mean age of $64.3 \pm 13.4$ years (range 28-88 years). The control group consisted of 28 subjects (13 men and 15 women) with a mean age of $64.5 \pm 17.4$ years (range 30-83 years) (Table 2). Details of antiglaucoma eyedrops of enrolled patients are shown in Table 1.

Table 2 The culture-positive rate in glaucoma eyedrop and control groups

\begin{tabular}{llll}
\hline Group & $\begin{array}{l}\text { Total number } \\
\text { of eyes }\end{array}$ & $\begin{array}{l}\text { Culture- } \\
\text { positive rate }\end{array}$ & $\%$ \\
\hline Glaucoma eyedrop & 119 & 48 & $40.3 *$ \\
Male & 52 & 25 & 48.1 \\
Female & 67 & 23 & 34.3 \\
Control & 28 & 19 & 67.8 \\
Male & 13 & 9 & 69.2 \\
Female & 15 & 10 & 66.6 \\
\hline
\end{tabular}

Notes: The bacterial culture-positive rate in the glaucoma eyedrop group was significantly lower than in the control group. $* P<0.05,2 \times 2$ Chi square test.
The bacterial culture-positive rate was 40.3\% (48/119 eyes) in the glaucoma eye group and $67.8 \%$ (19/28 eyes) in the control group, being significantly lower in the eyedrop group $(P<0.05)$ (Table 2$)$. There was no significant difference in the culture-positive rate between men and women from the eyedrop group (48.1\% [25/52 eyes] for men and $34.3 \%$ [23/67 eyes] for women). In the control group, there was also no significant difference of the bacterial culture-positive rate between the genders $(69.2 \%$ [9/13 eyes] for men and $66.6 \%$ [10/15 eyes] for women). The culture-positive rate was lower in the glaucoma eyedrop group than in the control group for all age groups, but there were no significant differences between any two age groups.

In the glaucoma eyedrop group, ten bacterial species (57 strains) were detected from 48 eyes and 52 of these strains (91.3\%) were Gram-positive bacteria (Table 3). Coagulase-negative staphylococci such as Staphylococcus epidermidis (33 strains, 57.9\%) were the most frequently observed bacteria, followed by Corynebacterium diphtheriae (11 strains, 19.3\%), Propionibacterium acnes (four strains, 7.0\%), Group B Streptococcus (three strains, 5.3\%), and methicillin-sensitive Staphylococcus aureus (one strain, 1.8\%). Gram-negative bacteria included Haemophilus influenzae (two strains, 3.5\%), Serratia marcescens (one strain, 1.8\%), Enterobacter spp. (one strain, 1.8\%), and Stenotrophomonas maltophilia (one strain, 1.8\%).

In the control group, four bacterial species (28 strains) were identified from 19 eyes. All of these were Gram-positive, including coagulase-negative staphylococci (14 strains, $50.0 \%$ ), C. diphtheriae (seven strains, 25.0\%), Group B streptococcus (six strains, 21.4\%), methicillin-sensitive $S$. aureus (six strains, 21.4\%), and Finegoldia magna (one strain, $3.6 \%$ ) (Table 3 ). The two most frequently detected bacteria

Table 3 Bacterial isolates from the glaucoma eyedrop and control groups

\begin{tabular}{|c|c|c|}
\hline & $\begin{array}{l}\text { Glaucoma } \\
\text { eyedrop }\end{array}$ & Control \\
\hline Gram-positive bacteria & $52(91.3 \%)$ & $28(100 \%)$ \\
\hline Coagulase-negative staphylococci & $33(57.9 \%)$ & I 4 (50.0\%) \\
\hline Corynebacterium spp. & II (19.3\%) & $7(25.0 \%)$ \\
\hline Propionibacterium acnes & $4(7.0 \%)$ & \\
\hline Group B Streptococcus & $3(5.3 \%)$ & $6(21.4 \%)$ \\
\hline Staphylococcus aureus & $\mathrm{I}(\mathrm{I} .8 \%)$ & $6(21.4 \%)^{*}$ \\
\hline Finegoldia magna & & I (3.6\%) \\
\hline Gram-negative bacteria & $5(8.9 \%)$ & $0(0 \%)$ \\
\hline Haemophilus influenzae & $2(3.5 \%)$ & \\
\hline Serratia marcescens & $\mathrm{I}(\mathrm{I} .8 \%)$ & \\
\hline Enterobacter spp. & I (I.8\%) & \\
\hline Stenotrophomonas maltophilia & $\mathrm{I}(\mathrm{I} .8 \%)$ & \\
\hline
\end{tabular}

Note: $* P<0.05$. 
were the same as in the glaucoma eyedrop group. The results were similar to those obtained in a study conducted at the authors' institution in 1998 where conjunctival sac bacteria were isolated from patients who were not using eyedrops while awaiting cataract surgery (unpublished data). In the present study, the isolation rate of $S$. aureus was significantly higher in the control group $(21.4 \%)$ than in the glaucoma eyedrop group $(1.8 \% ; P<0.05)$, but methicillin-resistant $S$. aureus was not identified in either group.

The culture-positive rate was significantly lower in the glaucoma eyedrop group than in the control group $(P<0.01)$. There were no significant differences in the culture-positive rate among subgroups of subjects stratified by frequency of instillation per day (Table 4), nor stratified by the number of eyedrop medications (Table 5).

Furthermore, in the glaucoma eyedrop group, comparison of the patients using eyedrops containing $\geq 0.01 \%$ benzalkonium chloride (latanoprost, nipradilol, unoprostone, betaxolol hydrochloride) with those using eyedrops containing $<0.01 \%$ benzalkonium chloride revealed that there was no significant difference in the bacterial culturepositive rate (data not shown). When the total daily dose of benzalkonium chloride was calculated by multiplying the concentration in each eyedrop preparation by the frequency and volume of dosing, there were no significant differences among subgroups stratified by total dose. Damage to the corneal epithelium is an ophthalmologic disorder that may be associated with benzalkonium chloride. Such damage was observed in $45 / 86$ eyes $(52.3 \%)$ of the 86 subjects who could be retrospectively evaluated, including superficial punctate keratopathy (Figure 1) in 43 eyes $(50.0 \%)$ and corneal epithelial erosions in two eyes $(2.3 \%)$.

The percentage of strains for which drug sensitivity was determined was similar in both groups (40/57 strains

Table 4 Frequency of instillation per day and bacterial detection rate

\begin{tabular}{llll}
\hline $\begin{array}{l}\text { Frequency of } \\
\text { instillation/day }\end{array}$ & $\begin{array}{l}\text { Total number } \\
\text { of eyes }\end{array}$ & $\begin{array}{l}\text { Culture-positive } \\
\text { rate }\end{array}$ & $\%$ \\
\hline 0 & 19 & 28 & 67.8 \\
1 & 3 & 9 & 33.3 \\
2 & 16 & 40 & 40.0 \\
3 & 8 & 19 & 42.1 \\
4 & 5 & 21 & 23.8 \\
5 & 4 & 8 & 50.0 \\
6 & 4 & 15 & 26.7 \\
7 & 1 & 3 & 33.3 \\
8 & 1 & 3 & 33.3 \\
9 & 0 & 1 & 0 \\
\hline
\end{tabular}

Note: There were no significant differences.
Table 5 The number of antiglaucoma eyedrops per day and bacterial detection rate

\begin{tabular}{llll}
\hline $\begin{array}{l}\text { Number of } \\
\text { eyedrops }\end{array}$ & $\begin{array}{l}\text { Total number } \\
\text { of eyes }\end{array}$ & $\begin{array}{l}\text { Culture-positive } \\
\text { rate }\end{array}$ & $\%$ \\
\hline I & 19 & 49 & 38.8 \\
2 & 27 & 39 & 69.2 \\
3 & 17 & 27 & 63.0 \\
4 & I & 4 & 25.0 \\
\hline
\end{tabular}

Note: There were no significant differences.

[70.2\%] in the glaucoma eyedrop group and 19/28 strains [67.9\%] in the control group). Resistance to levofloxacin was significantly lower in the glaucoma eyedrop group $(6 / 40$ strains, $15.0 \%)$ than in the control group (11/19 strains, $57.9 \%)(P<0.05)$.

\section{Discussion}

It has been suggested that instillation of eyedrops can decrease the culture-positive rate of bacteria. The present study of subjects treated with glaucoma eyedrops for 1 year or more yielded findings consistent with this, since fewer bacteria were detected in the subjects using eyedrops. In a previous study, the conjunctival culture-positive rate was higher in patients with glaucoma than in the healthy controls. ${ }^{10}$ However, there are some differences between these studies which should be noted. The follow-up period was twice as long in the present study than the previous study. Also, patients with diabetes mellitus and patients treated with corticosteroids were excluded in the present study.

Comparisons between subgroups stratified by the number of drugs or the concentration of benzalkonium chloride in the eyedrops showed no statistically significant differences

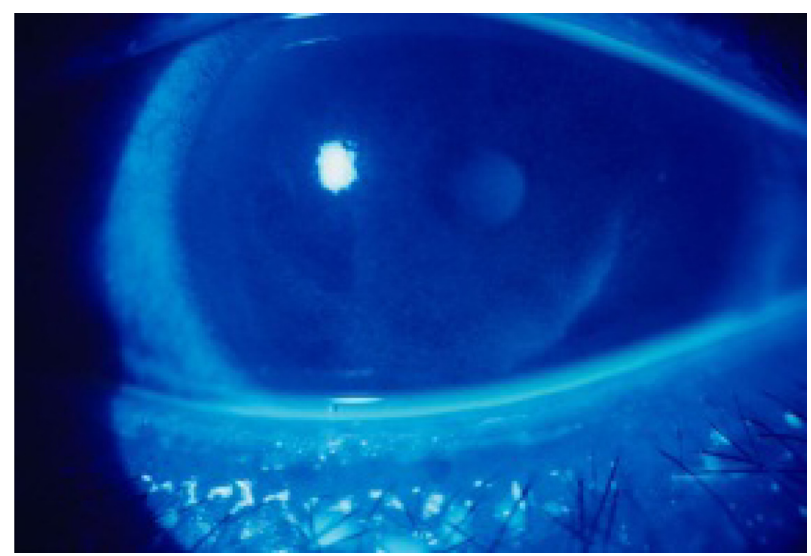

Figure I Corneal epithelial damage associated with glaucoma eyedrops. The right eye was stained by fluorescein solution for ophthalmological diagnosis. A 51 -yearold man had glaucoma in both eyes and was treated by unoprostone isopropyl $0.12 \%$ which included $0.01 \%$ benzalkonium chloride. It was shown in both eyes and treated with hyaluronic acid eyedrops without benzalkonium chloride. 
in the bacterial culture-positive rate. These findings suggest that eyedrops achieve a disinfectant or sterilizing effect even when only one type is used or when eyedrops that have a low antiseptic content are employed, and this effect is not much enhanced when the number of types of eyedrops is increased. Before performing this study, it was expected that subjects who frequently instilled eyedrops might have lower bacterial culture-positive rates due to a washout effect. However, it was found that the frequency of instillation does not affect the culture-positive rate, suggesting that the sterilizing effect of antiseptic in eyedrops was more important.

Since glaucoma patients are usually treated with eyedrops for a long period, the effect of antiseptics in these drops on the conjunctival bacterial flora should be evaluated carefully. ${ }^{1-4,10} \mathrm{An}$ important finding of the present study was the detection of Gram-negative bacteria in the glaucoma eyedrop group. This suggests that antiseptics affect the bacterial flora residing on the ocular surface, perhaps by microbial substitution. On the other hand, it is intriguing that resistance to levofloxacin was significantly lower in the glaucoma eyedrop group than in the control group. This may make sense in theory because benzalkonium chloride is an antiseptic rather than an antimicrobial agent, therefore the bacteria should not acquire resistance. However, it is not known why the rate of levofloxacin resistance was lower in the glaucoma eyedrop group. Bacterial drug resistance poses an increasing problem in clinical practice. Antiseptics such as benzalkonium chloride, which has a sterilizing effect and appears to reduce drug resistance, may have some advantages in the clinical setting.

The bactericidal effect of benzalkonium chloride depends on the positively-charged drug adsorbing and causing the degeneration of negatively-charged bacteria. Benzalkonium chloride has a bactericidal effect on most bacteria, except for tuberculosis and spore-forming bacteria. It has no effect on viruses and fungi, which are not negatively-charged, as well as no effect on Pseudomonas aeruginosa and some methicillin-resistant S. aureus. Benzalkonium chloride is thus an antiseptic with limited efficacy, so caution should be used when estimating its influence as an antiseptic in eyedrops. There have been several reports about bacterial contamination in the bottle of eyedrops that occurred after prolonged use, ${ }^{11,12}$ although this was not a concern in the present study.

Hori et al reported that the bacterial culture-positive rate was the same in healthy subjects and in patients with dry eyes who were using artificial tears that did not contain antiseptics, but resistance to levofloxacin was higher in the patients..$^{13}$ It has not been determined whether this is due to changes of the ocular surface in the patients with dry eyes or is caused by bacterial contamination from the fingers or eyelids of patients using eyedrops. ${ }^{11,12}$ The present study yielded the contrary result that chronic instillation of eyedrops for glaucoma containing an antiseptic led to lower resistance to levofloxacin.

To avoid conjunctival and corneal damage, a benzalkonium chloride concentration of $0.01 \%-0.05 \%$ is recommended, although the concentration in most eyedrops is below this recommended range. ${ }^{14}$ However, corneal epithelial damage that was probably caused by benzalkonium chloride was observed in about half of subjects as a complication of eyedrop therapy. Particular attention should be paid to this finding with regard to the sensitivity of the ocular surface.

It is known that the culture-positive rate of ocular bacteria increases with age. Age-related changes include a decrease of resistance and immune function, decreased lacrimation, and impaired self-cleansing of the ocular surface due to narrowing of the nasolacrimal duct. However, no differences in the bacterial culture-positive rate among different age groups in the glaucoma eyedrop group were found. Thus, washing out of bacteria after instillation of eyedrops may compensate for impaired self-cleansing of the ocular surface.

The present study investigated the effect of benzalkonium chloride as an antiseptic in glaucoma eyedrops. Future studies should investigate the effects and side effects of active ingredients, and the effects on conjunctival bacterial flora of other vehicles, antiseptics, activating agents, and their combinations. Furthermore, newer drug combinations requiring less instillation frequency are being increasingly used, and any changes associated with these new formulations should be monitored. In particular, less instillation frequency caused by fixed combinations of antiglaucoma eyedrops will offer the potential of maximizing patient adherence by decreasing the burden of using multiple topical agents. ${ }^{15,16}$ The incidence of ocular surface disorder caused by antiglaucoma eyedrops may also decrease. The present study may be one of the last performed in the era when common eyedrops for glaucoma contain only one active ingredient.

\section{Disclosure}

The authors report no conflicts of interest in this work.

\section{References}

1. Noecker R. Effects of common ophthalmic preservatives on ocular health Adv Ther. 2001;18(5):205-215.

2. Noecker RJ, Herrygers LA, Anwaruddin R. Corneal and conjunctival changes caused by commonly used glaucoma medications. Cornea. 2004; 23(5):490-496. 
3. Baudouin C. Detrimental effect of preservatives in eyedrops: implications for the treatment of glaucoma. Acta Ophthalmol. 2008;86(7): 716-726.

4. Epstein SP, Ahdoot M, Yee K, Marcus E, Asbell PA. Comparative toxicity of preservatives on immortalized corneal and conjunctival epithelial cells. J Ocul Pharmacol Ther. 2009;25(2):113-119.

5. Martins EN, Alvarenga LS, Höfling-Lima AL, et al. Aerobic bacterial conjunctival flora in diabetic patients. Cornea. 2004;23(2):136-142.

6. Toshida H, Kogure N, Inoue N, Murakami A. Trends in microbial keratitis in Japan. Eye Contact Lens. 2007;33(2):70-73.

7. Inoue N, Toshida H, Mamada N, Kogure N, Murakami A. Contact lensinduced infectious keratitis in Japan. Eye Contact Lens. 2007;33(2): 65-69.

8. National Committee for Clinical Laboratory Standards. Performance standards for antimicrobial disk susceptibility tests. Approved standard, 7th ed. NCCLS Document M2-M7. Wayne, PA: NCCLS; 2000.

9. National Committee for Clinical Laboratory Standards. Performance standards for antimicrobial disk susceptibility testing. Eleventh informational supplement. NCCLS Document M100-S11. Wayne, PA: NCCLS; 2001.
10. Sen EM, Yilmaz MB, Dansuk Z, et al. Effect of chronic topical glaucoma medications on aerobic conjunctival bacterial flora. Cornea. 2009;28(3): 266-270.

11. Orna G, Bottone EJ, Podos SM, Schumer RA, Asbell PA. Microbial contamination of medications used to treat glaucoma. Br J Ophthalmol. 1995;79(4):376-379.

12. Jokl DH, Wormser GP, Nichols NS, Montecalvo MA, Karmen CL. Bacterial contamination of ophthalmic solutions used in an extended care facility. Br J Ophthalmol. 2007;91(10):1308-1310.

13. Hori Y, Maeda N, Sakamoto M, Koh S, Inoue T, Tano Y. Bacteriologic profile of the conjunctiva in the patients with dry eye. Am JOphthalmol. 2008;146(5):729-734.

14. Rhee DJ, Rapuano CJ, Belzer TL, Fraunfelder FW, editors. Physicians' desk reference for ophthalmic medicines. 33rd ed. Montvale, NJ: Thomson PDR; 2005.

15. Noecker RJ,Awadallah NS, Kahook MY. Travoprost $0.004 \% /$ timolol $0.5 \%$ fixed combination. Drugs Today (Barc). 2007;43(2):77-83.

16. Robin AL, Novack GD, Covert DW, Crockett RS, Marcic TS. Adherence in glaucoma: objective measurements of once-daily and adjunctive medication use. Am J Ophthalmol. 2007;144(4):533-540.

\section{Publish your work in this journal}

Infection and Drug Resistance is an international, peer-reviewed openaccess journal that focuses on the optimal treatment of infection (bacterial, fungal and viral) and the development and institution of preventive strategies to minimize the development and spread of resistance. The journal is specifically concerned with the epidemiology of antibiotic

\section{Dovepress}

resistance and the mechanisms of resistance development and diffusion in both hospitals and the community. The manuscript management system is completely online and includes a very quick and fair peerreview system, which is all easy to use. Visit http://www.dovepress.com/ testimonials.php to read real quotes from published authors. 